\title{
IMPLEMENTASI IOT PADA VERTICAL GARDEN DENGAN MENGGUNAKAN FUZZY UNTUK MEMELIHARA TANAMAN KANGKUNG
}

\author{
William Kurniawan, Suryo Adi Wibowo, Deddy Rudhistiar \\ Program Studi Teknik Informatika S1, Fakultas Teknologi Industri \\ Institut Teknologi Nasional Malang, Jalan Raya Karanglo km 2 Malang, Indonesia \\ Williamkurniawan10@gmail.com
}

\begin{abstract}
ABSTRAK
Terbatasnya Lahan pertanian di Indonesia khususnya di perkotaan semakin banyak berkurang dan berubah fungsi di buktikan fungsi lahan pertanian yang menjadi perkantoran, perumahan, perindustrian, dan sector lainnya. Semua itu mendorong berbagai macam inovasi dalam bidang pertanian dengan perpaduan teknologi kea rah yang semakin modern, Untuk menjawab permasalah tersebut, Penelitian dan pengembangan telah di lakukan, salah satunya adalah menggunakan penanaman dengan sistem Hidroponik. Hidroponik adalah metode penanaman tanaman tanpa menggunakan media Tanah dalam proses pertumbuhannya. Pada sistem hidroponik aspek penting yang perlu di perhatikan adalah pengelolaan nutrisi dan $\mathrm{Ph}$. Untuk pengelolaan Nutrisi penulis menggunakan Sensor TDS yang dingunakan untuk mengatur kepekatan larutan nutrisi dalam Satuan PPM dan Menggunakan Ph meter sensor untuk mengukur kadar ph air. Mikrokontroller yang digunakan adalah NodeMcu. Dengan penerapan teknologi IoT (Internet of Things). Hasil dari penelitian ini adalah mikroontroler berhasil berjalan dengan baik dengan Website dan database yang bisa melakukan komikasi serial dengan baik dan tepat. Sistem control dan monitoring $\mathrm{Ph}$, Kepekatan dan pendeteksi ketersediaan air berjalan sesuai setpoint yang di tentukan oleh user, Nilai yang di dapat dari dari pengetesan sensor TDS memiliki rata rata error 2,97\% artinya memiliki nilai error yang cukup kecil dan keangkurangan nilai rata rata $94 \%$ artinya sensor yang di ngunakan sudah berjalan dengan cukup baik User Interface yang digunakan sederhana dan mudah dimengerti.
\end{abstract}

Kata Kunci : Internet of things, Mickrokontroller, Hidroponik, Vertical Garden, PH Sensor, Tds Sensor, Website

\section{PENDAHULUAN}

Peminat tanaman di berbagai dunia sangat banyak bahkan semakin familiar dan menjadi hal yang wajib atau wajar untuk memelihara tanaman di rumah mau pun di tempat yang kita tinggali,

Vertical Garden Sendiri adalah konsep taman tegak, yaitu tanaman yang di buat sedemikian rupa sehingga menyerupain taman dalam bidang tegak. Vertical garden atau hidroponik adalah salah satu metode dalam bididaya menanam dengan memanfaatkan air tanpa menggunkan media tanah dengan menekankan nutrisi yang terkandung di dalam air untuk memilihara tanaman tersebut.,

Budidaya hidroponik saat ini sangat terkenal, sehingga banyak cara ataupun teknik yang digunakan dalam budidaya hidroponik, mulai dari teknik wick, DFT (Deep Flow Technique), NFT (Nutrient Film Technique), aeroponics, drip system, fertigasi, bubbleponics dan bioponik [1] merupakan teknik yang paling sering dipakai oleh petani.

Penulis menggunakan teknik DFT dalam penelitian ini yang dimana memiliki kelebihan dan keuntungan. Kelebihan dari teknik DFT lebih menghemat daya listrik karena air nutrisi dapat disimpan sementara, sedangkan kekurangannya Teknik DFT memerlukan lebih banyak penggunaan Nutrisi,

. Banyak masalah yang terjadi pada perawatan tanaman di rumah tangga maupun industri pembibitan tanaman, salah satunya adalah tanaman Hidroponik yang mati karena pengairan air yang tidak tepat. . Karena itulah timbul ide untuk membuat system yang dapat memelihara tanaman pada vertical garden dengan menerapkan IoT berbasi Arduino dengan sensor Kepada kepadatan dari Air yang dingunakan, serta sensor $\mathrm{Ph}$ untuk mengatur kadar ph yang di ngunakan untuk mengairi tanaman pas dan tepat dan dalam mengairinya pun menggukan waterpum atau electric valve, Sehingga system yang di buat bisa memudahkan manusia dalam perawatannya dan bisa menggunakan waktunya untuk melakukan aktivitas lain.

\section{TINJAUAN PUSTAKA}

\subsection{Penelitian Terdahulu}

Adapun Penelitian yang sama Telah di lakukan sebelumnya oleh Zettry Buana dkk (2019) dengan Judul "Sistem Pemantaun Tanaman Sayur Dengan Media Tanama Hidroponik Menggunakan Arduino" Penelitian ini bertujuan untuk membantu mengantisipasi terjadinya penurunan kualitas tanaman sayur tersebut mengalami penurunan kualitas tanaman sayur tersebut denga memanfaatkan teknologi di mana saat ini teknologi sudah berkembang denga sangat pesat. Kesamaan dalam penelitian ini adaah menggunakan sensor yang sama menggunakan sensor Ph air yang mana sensor ini berfungsi untuk memantau tingkat keasaman pada 
cairan nutrisi tanaman hidroponik, Hasil dari pengujian sensor $\mathrm{Ph}$ pada mengujian ini sudah baik nilai yang terukur pada air mendekati Nilai $\mathrm{Ph}$ yang di butuhkan. [1]

Penelitian Oleh Suryo Adi Wibowo (2018) Pada penelitian selanjutnya dengan judul "Implementasi Aplikasi Perhitungan Kebutuhan kalori Penderita Diabetes Melitus Di lingkungan Klinik" adapun dalam jurnal ini menerapkan Fuzzy logic yang di harapkan mampu memperkirakan jumlah asupan kalori penyakit diabetes mellitus secara konsisten cepat serta tepat, dimana kesama pada penelitian ini ada menggunakan metode fuzzy dalam mengukur tingkat nutrisi yang di butuhkan pada tanaman agar tepat dengan memanfaatkan Sensor TDS.

Penelitian oleh Joseph Dedy Irawan, dkk (2018) pada penelitian selanjutnya dengan judul “ Implementasi Iot Pada Remote Monitoring dan Controlling Green House" adapun dalam jurnal ini menerapkan green house yang di mana bertujuan perkembangannya teknologi dapat dibuat suatu alternatif memanfaatkan lahan kecil dengan hasil maksimal salah satu caranya adalah dengan menggunakan greenhouse yang menerapkan IoT, adapun kesamaan di dalam penelitian ini adalah sama sama memanfaatkan lahan yang minim dengan hasil yang maksimal dan juga penerapan Iot pada Implementasinya.[3]

Bagas Pratama (2018) pada penelitian selanjutnya dengan judul "Rancang Bangun Kandang Ternak Burung Otomatis Berbasis Arduino " Penelitian ini bertujuan untuk membuat sebuah sistem yang dapat memberi pakan dan minum secara otomatis, salah satu sensor yang dingunakan dalam penelitian ini adalah Sensor water level yang berfungsi untuk indicator ketersediaan air untuk memberi minum, Kesamaan dalam penelitian ini adalah sama sama menggunakan sensor water level untuk indicator ketersediaan air dalam proses sebuah pemeliharaan.[4]

Penelitian Oleh Dian Panca (2016) pada penelitian selanjutnya dengan judul "Implementasi Fuzzy Logic Controller Untuk Mengatur Ph Nutrisi Pada Sistem Hidroponik Nutrient Film Technique (Nft)" adapun dalam jurnal ini membuat sebuah sistem hidroponik dengan sistem Nft Metode ini memiliki kelebihan yaitu memanfaatkan air yang tersirkulasi sebagai media tanam agar memperoleh air, nutrisi dan oksigen sehingga mampu mempercepat pertumbuhan tanaman dengan hasil yang baik. Adapun kesamaan dalam penelitian ini membuat sebuah sistem hidroponik perbedaannya penulis di sini menggunakan metode DFT dimana memiliki keuntungan lebih hemat listrik dan tanaman terus mendapatkan nutrisi walupun waterpump untuk pengairan mati karna adanya air yang tertampung di pipa. [5]

\subsection{Internet of Things}

Internet of Things (IoT) adalah suatu konsep dimana konektifitas internet dapat bertukar informasi satu sama lainnya dengan benda-benda yang ada disekelilingnya. Banyak yang memprediksi bahwa Internet of Things (IoT) merupakan "the next big thing" di dunia teknologi informasi. Hal ini dikarenakan banyak sekali potensi yang bisa dikembangkan dengan teknologi Internet of Things (IoT) tersebut. Bagi Anda yang belum mengerti lebih jauh, Teknologi Internet of Things (IoT) diibaratkan dimana alat-alat fisik bisa terkoneksi dengan internet. Misalnya, Kulkas, TV, Mesin Cuci dan lainnya dapat di kontrol menggunakan smartphone untuk mematikan, menghidupkan dan kegiatan lainnya.

\subsection{Monitoring}

Monitoring adalah proses pengumpulan dan analisis informasi berdasarkan indikator yang ditetapkan secara sistematis dan kontinu tentang kegiatan/ program sehingga dapat dilakukan tindakan koreksi untuk penyempurnaan program/ kegiatanitu selanjutnya. Monitoring adalah pemantauan yang dapat dijelaskan sebagai kesadaran (awareness) tentang apa yang ingin diketahui, pemantauan berkadar tingkat tinggi dilakukan agar dapat membuat pengukuran melalui waktu yang menunjukkan pergerakan kearah tujuan atau menjauh dari itu. Monitoring akan memberikan informasi tentang status dan kecenderungan bahwa pengukuran dan evaluasi yang diselesaikan berulang dari waktu ke waktu, pemantauan umumnya dilakukanuntuk tujuan tertentu, untuk memeriksa terhadap proses berikut objek atau untuk mengevaluasi kondisi atau kemajuan menuju tujuan hasil manajemen atas efek tindakan dari beberapa jenis antara lain tindakan untuk mempertahankan manajemen yang sedang berjalan [2].

\subsection{Vertical Garden}

Vertical garden merupakan taman yang dibangun pada bidang yang berdiri tegak lurus dengan tanah. Hal inilah yang membuat vertical garden sering juga disebut dengan model taman dinding. Vertical garden di Indonesia juga sering disebut dengan taman dinding, green wall, vertical landscape, living wall, dan lain sebagainya. Secara sederhana, vertical garden berbeda dengan model taman horizontal yang kita kenal selama ini karena ditanam secara vertikal atau tegak lurus. Salah satu Tujuan dari vertical garden adalah untuk mengatasi keterbatasan lahan.

\subsection{Pot Hidroponik}

Di bawah ini adalah desain dari pot hidroponik yang akan di ngunakan pada project penulis ukuran dari pot hidroponik ini adalah $90 \times 100 \mathrm{CM}$. 


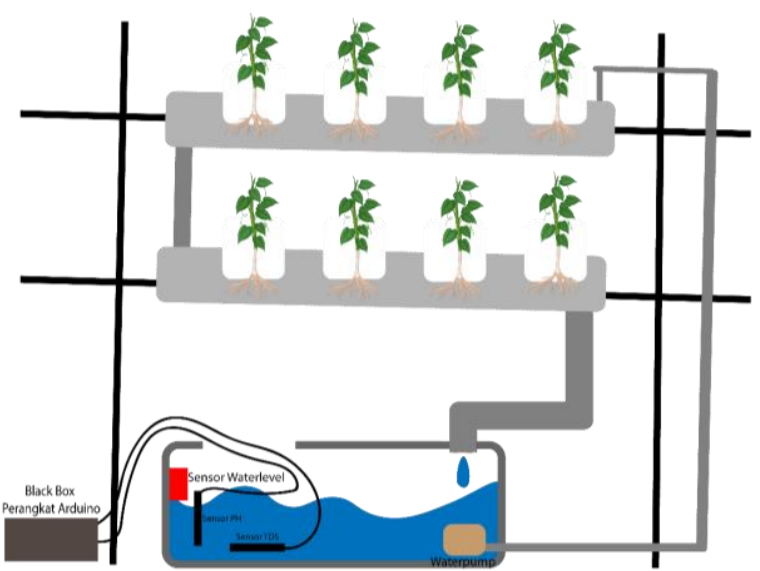

Gambar 1. Pot Hidroponik

\subsection{NodeMcu}

NodeMcu merupakan sebuah opensource platform IoT dan pengembangan Kit yang menggunakan bahasa pemrograman Lua untuk membantu programmer dalam membuat prototype produk IoT atau bisa dengan memakai sketch dengan arduino IDE.

Pada NodeMcu dilengkapi dengan micro usb port yang berfungsi untuk pemorgaman maupun power supply. Selain itu juga pada NodeMCU di lengkapi dengan tombol push button yaitu tombol reset dan flash

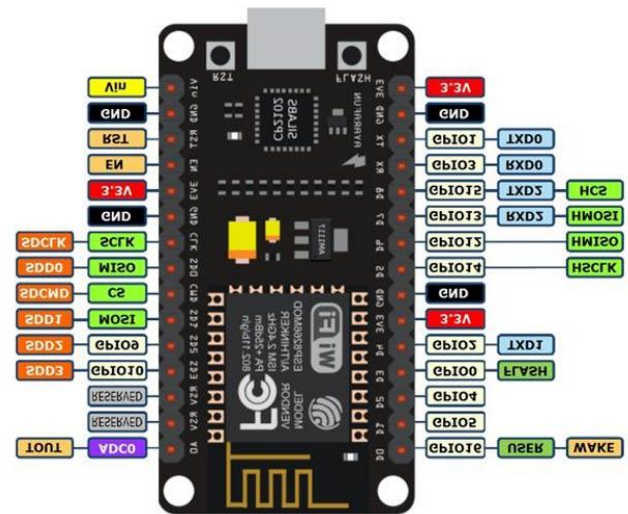

Gambar 2. NodeMcu

\subsection{Sensor TDS (Total Dissolve Solid)}

Merupakan sensor kompatibel Arduino yang digunkan untuk mengukur kadar TDS (Total Dissolve Solid) pada air. TDS sendiri merupakan kadar konsentrasi objek solid yang terlarut dalam air. Semakin tinggi nilai TDS nya maka semakin keruh airnya, begitupun sebaliknya. Semakin rendah nilai TDS nya maka semakin jernih pula air tersebut.

Dengan Analog TDS Sensor/Meter for Arduino, Anda bisa membuat sendiri TDS meter di rumah menggunkan Arduino atau mikrokontroler sejenis. Sensor ini mendukung input tegangan antara $3.3-5 \mathrm{~V}$, serta output tegangan analog yang dihasilkan berkisar pada 0 - 2.3V. Sangat cocok untuk aplikasi manajemen kualitas air, hidroponik, dsb.

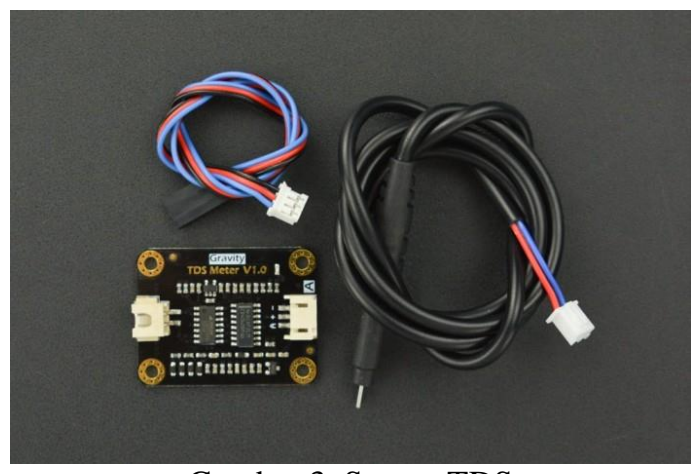

Gambar 3. Sensor TDS

2.8. Relay

Modul relay merupakan salah satu alat yang berperan berdasarkan prinsip elektromagnetik untuk menggerakkan konektor guna memindahkan posisi $O N$ ke $O F F$ atau sebaliknya dengan memanfaatkan tenaga listrik. Efek induksi magnet dari kumparan induksi listrik yang terjadi mengakibatkan pristiwa tertutup dan terbukanya kontaktor. Perbedaan yang paling mendasar antara relay dan sakelar adalah pada saat pemindahan dari posisi $O N$ ke $O F F$. Relay melakukan pemindahan-nya secara otomatis dengan arus listrik, sedangkan sakelar dilakukan dengan cara manual.

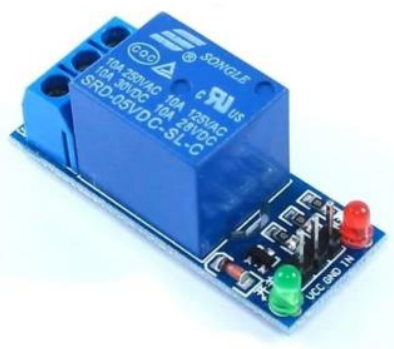

Gambar 4. Relay

\section{METODE PENELITIAN}

\subsection{Logika Fuzzy}

Logika Fuzy merupakan metodologi system control pemecahan masalah yang cocok untuk di Implementasikan ke system mulai dari system yang sederhana, Sistem kecil, embedded system, atau workstation berbasis akusisi data.

Metodologi ini dapat diterapkan pada perangkat keras, perangkat lunak, atau kombinasi keduanya. Dalam logika klasik dinyatakan bahwa segala sesuatu bersifat biner yang artinya hanya mempunyai dua kemungkinan, "ya atau tidak", "benar atau salah", "baik atau buruk", dan lain-lain. Oleh karena itu, semua ini dapat mempunyai nilai keanggotaan 0 atau 1. Akan tetapi, dalam logika fuzzy memungkinkan nilai 


\subsection{Blok Diagram Sistem}

Blok diagram adalah diagram dari sebuah sistem, di mana bagian sensor $\mathrm{Ph}$ air, Waterlevel, dan Tds Sensor sebagai alat masukan untuk mendeteksi Air, NodeMcu sebagai alat pemrosesan, Waterpump sebagai alat tambahan yang di ngunakan untuk output. Proses kerja pada alat ini di tunjukan pada gambar 5

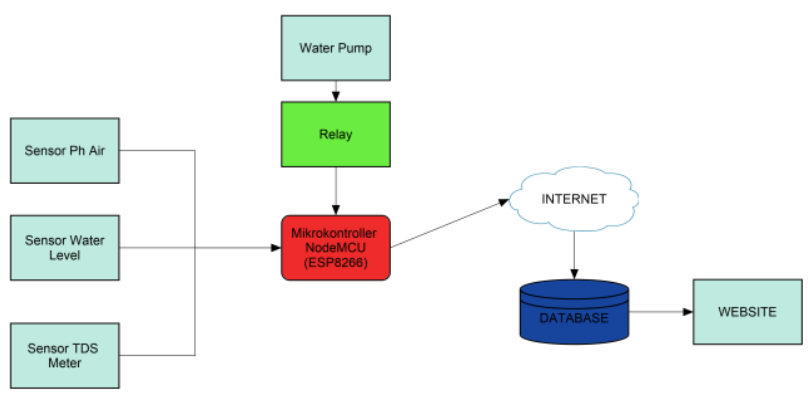

Gambar 5. Blok diagram sistem

\subsection{Flowchart Sistem}

Flowchart sistem ini menjelaskan proses berjalananya aplikasi seperti ditunjukkan pada Gambar 6.

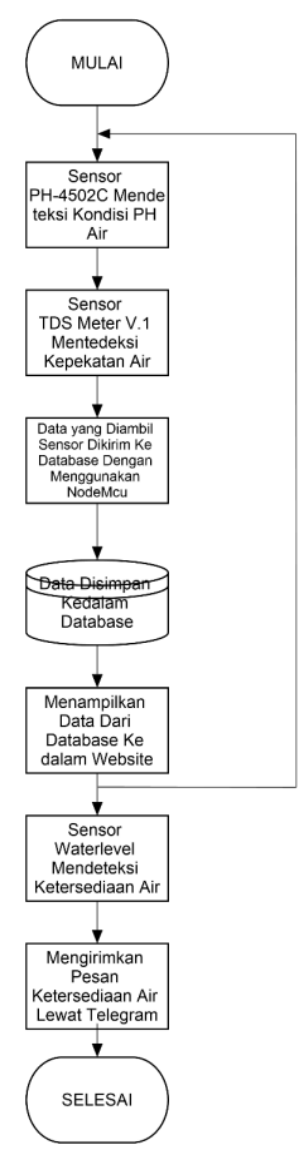

Gambar 6. Flowchart Sistem

Berdasarkan flowchart pada gambar 6, sistem dimulai dengan mengisialisasikan sensor $\mathrm{Ph}$ dan $\mathrm{Tds}$ dimana sensor akan mendeteksi konsidisi Ph air dan kepekatan Air, kemudian jika keadaan sudah terpenuhi maka sistem akan berjalan sesuai dengan yang sudah di programkan.

\subsection{Flowchart Alat}

Adapun alur proses cara kerja alat dijelaskan pada gambar 7

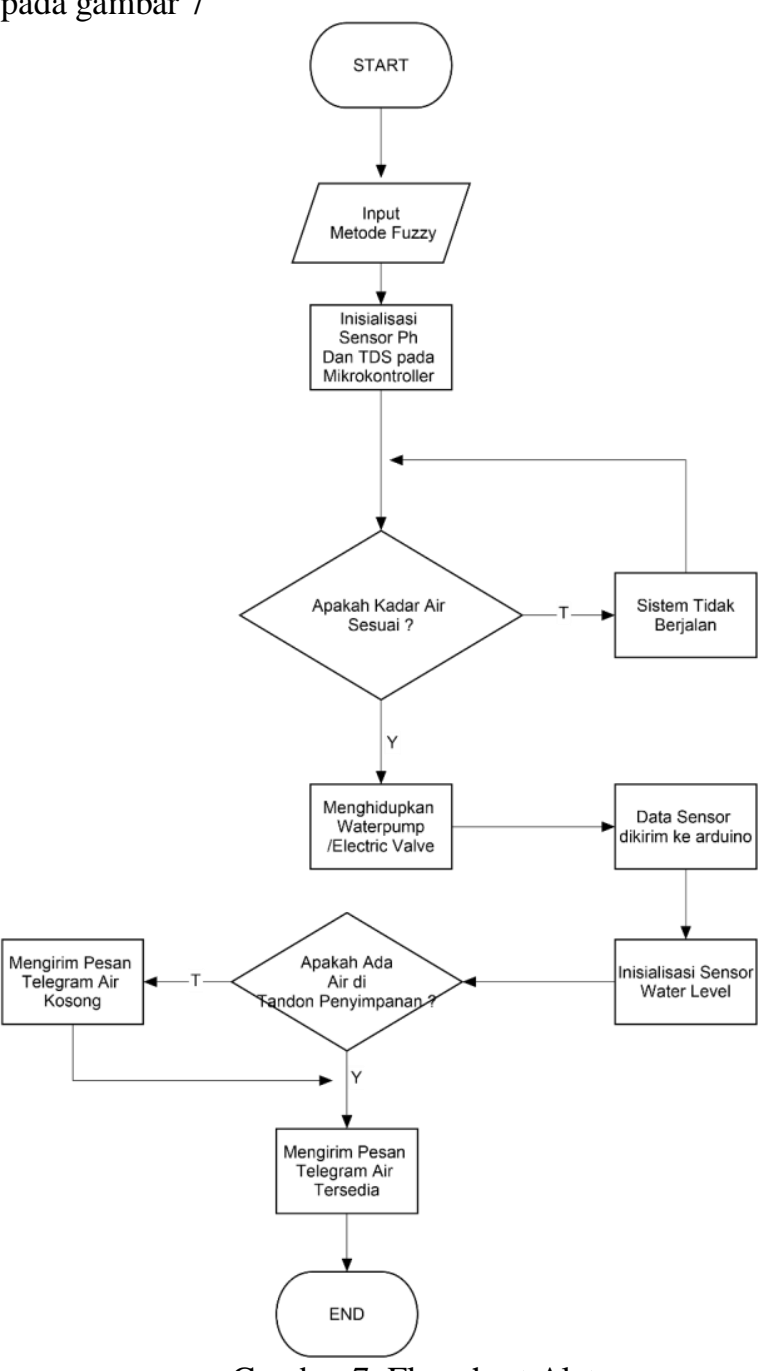

Gambar 7. Flowchart Alat

Gambar alur proses alat merupakan diagram alur pada system Vertical garden berbasis Arduino, dalam diagram alir ini menceritakan proses kerja sensor yang terjadi pada sistem di awali dengan mengimplementasikan Metode fuzzy pada siste Vertical garden berbasis arduno ini, lalu sensor $\mathrm{Ph}$ air dan TDS akan mengambil keputusan apakah air yang di ngunakan sudah sesuai untuk memberi nutris pada tanaman kangkung jia Y maka elevtric valve akan bekerja jika T maka proses akan di ulangi sampai air sudah terdeteksi sesuai untuk tanaman yang di tanami, Sensor water level mendeteksi jika tempat penyimpanan air sudah cukup untuk kapasitas tampung, Jika tempat penyimpanan air sudah cukup maka aliran air akan ke tempat penampuangan air akan di hentikan. 


\subsection{Data Flow Diagram}

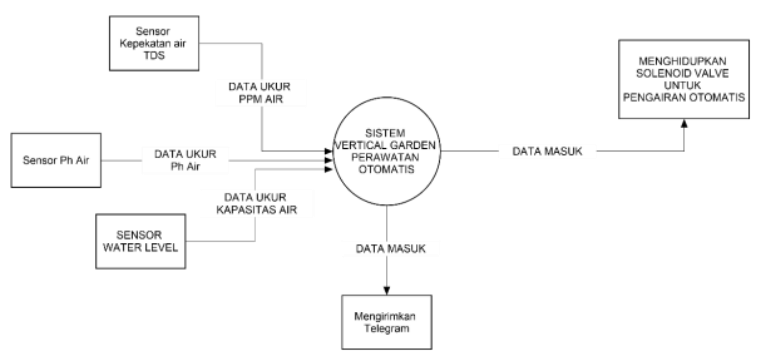

Gambar 8. DFD lvl 0

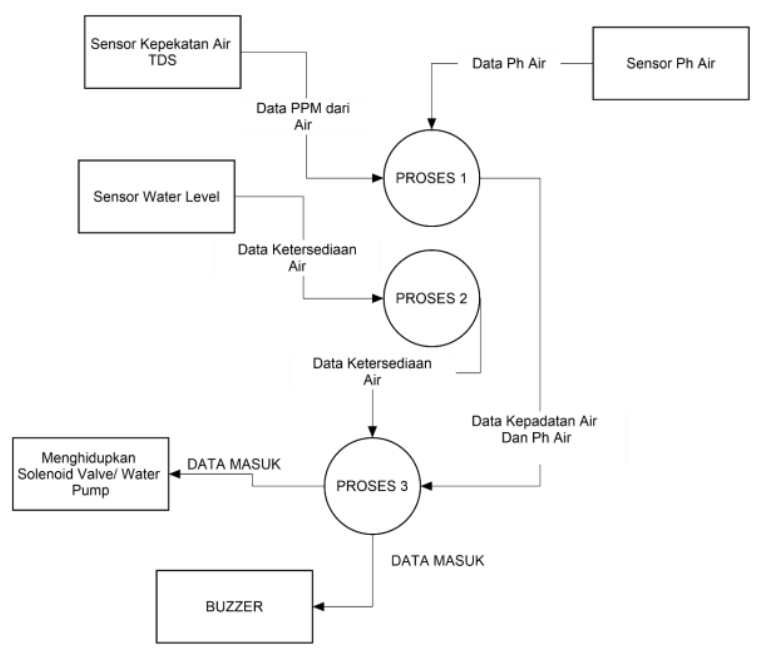

Gambar 9. DFD lvl 1

\section{IMPLEMENTASI DAN PENGUJIAN}

\subsection{Implementasi}

Halaman Monitoring merupakan Halaman yang menampilkan Data dari sensor yang menunjukan data dari Tds Sensor dan Ph Sensor.
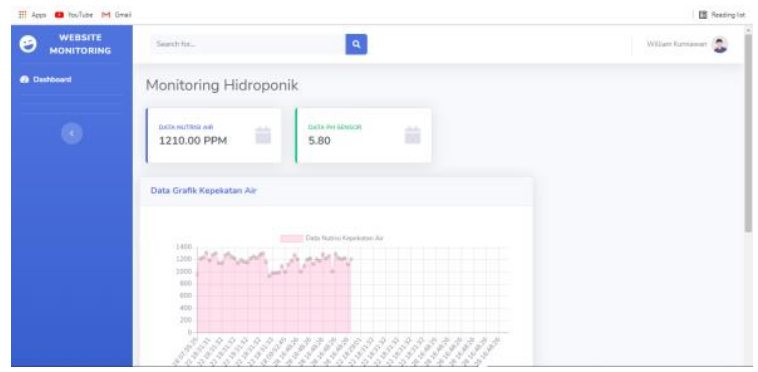

Gambar 10. Web Montoring

\subsection{Pengujian Fungsional}

Pengujian Fungsional di lakukan untuk mengetahui kinerja dari sensor alat apakah alat sudah bekerja dengan baik dan sesuai dengan hasil yang di inginkan oleh Peneliti dalam penelitiannya, untuk bisa menampilkan hasil dari sensor ke Website browser untuk memonitoring alat Pemeliharaan Vertical Garden

Bisa di lihat pada table 4.1 bahwa hasil yang inginkan sudah tercapai.
Tabel 1. Hasil pengujian Fungsional

\begin{tabular}{|c|l|c|c|c|}
\hline \multirow{2}{*}{ No } & \multicolumn{1}{|c|}{$\begin{array}{c}\text { Aspek } \\
\text { Pengujian }\end{array}$} & $\begin{array}{c}\text { Uc } \\
\text { Browser }\end{array}$ & $\begin{array}{c}\text { Google } \\
\text { Chrome } \\
\text { Version } \\
91.0 .4472 .106\end{array}$ & $\begin{array}{c}\text { Microsoft } \\
\text { Edge } \\
\text { Version } \\
91.0 .864 .48\end{array}$ \\
\hline & $\begin{array}{l}\text { Menampilkan } \\
\text { Kondisi PPM } \\
\text { air }\end{array}$ & $\checkmark$ & $\checkmark$ & $\checkmark$ \\
\hline 2 & $\begin{array}{l}\text { Menampilkan } \\
\text { Kondisi Ph } \\
\text { Air }\end{array}$ & $\checkmark$ & $\checkmark$ & $\checkmark$ \\
\hline 3 & $\begin{array}{l}\text { Menampilkan } \\
\text { Data Grafik } \\
\text { Sensor }\end{array}$ & $\checkmark$ & $\checkmark$ & $\checkmark$ \\
\hline 4 & Fungsi Home & $\checkmark$ & $\checkmark$ & $\checkmark$ \\
\hline
\end{tabular}

\subsection{Pengujian Sensor TDS}

Pengujian Sensor ph dilakukan dengan cara membandingkan pembacaan sensor dengan alat ukut Tds Meter, Sensor TDS berfungsi untuk mengambil nilai Nutrisi Pada air yang berfungsi untuk membuat pertumbuhan tanaman kangkung sampai Panen, Dimana nilai Kondisi yang optimal yang di butuhkan oleh tanaman kangkung untuk tumbuh adalah Ratarata 1050-1600 PPM. Di dapatkan hasil seperti pada gambar 11 di bawah ini.

Table 2. Pengujian Sensor TDS

\begin{tabular}{|c|c|c|c|c|c|}
\hline \multirow{2}{*}{ No } & \multirow{2}{*}{ Waktu } & Sensor & $\begin{array}{c}\text { TDS } \\
\text { Meter }\end{array}$ & \multirow{2}{*}{ Eror } & \multirow{2}{*}{ Keakuratan } \\
\cline { 3 - 5 } 1 & $09: 51: 44$ & 883 & 832 & $\begin{array}{c}6,129 \\
\%\end{array}$ & $93 \%$ \\
\hline 2 & $09: 52: 24$ & 900 & 908 & $\begin{array}{c}0,881 \\
\%\end{array}$ & $99,1 \%$ \\
\hline 3 & $09: 52: 45$ & 1001 & 987 & $\begin{array}{c}1,381 \\
\%\end{array}$ & $98 \%$ \\
\hline
\end{tabular}

\subsection{Pengujian Sensor $\mathbf{P h}$}

Pengujian sensor $\mathrm{Ph}$ di lakukan dengan cara membandingkan nilai pembacaan sensor dengan ph meter, untuk mengetahui nilai dari sensor ph apakah nilai ph sudah terbaca sesuai dengan sensor atau tidak sehingga dapat dilakukan proses penyiraman pada tanaman kangkung Nilai Yang di dapatkan adalah seperti tercantum di table.

Table 3. Pengujian Sensor PH

\begin{tabular}{|c|c|c|c|c|c|}
\hline \multirow{2}{*}{ No } & \multirow{2}{*}{ Waktu } & \multicolumn{2}{|c|}{ PH } & \multirow{2}{*}{ Eror } & \multirow{2}{*}{ Keakuratan } \\
\cline { 3 - 4 } & & Sensor & Ph Meter & & \\
\hline 1 & $10: 00: 2$ & 5.8 & 6.7 & $13,14 \%$ & $86,86 \%$ \\
\hline 2 & $10: 00: 5$ & 6.0 & 6.7 & $10 \%$ & $90 \%$ \\
\hline 3 & $10: 01: 01$ & 6.2 & 6.7 & $7,42 \%$ & $92,58 \%$ \\
\hline
\end{tabular}

\subsection{Pengujia Logika Fuzzy}

Dari Hasil percobaan yang telah dilakukan Untuk melakukan Pengujian logika fuzzy ke dalam sensor, didapatkan hasil pembacaan seperti pada table 4.4 di bawah ini. 
Tabel 4. Pengujian Logika Fuzzy

\begin{tabular}{|c|c|c|c|c|c|}
\hline \multirow{4}{*}{ No } & Input & \multicolumn{2}{|c|}{ Di Harapkan } & $\begin{array}{c}\text { Kenyat } \\
\text { aan }\end{array}$ & $\begin{array}{c}\text { Keterang } \\
\text { an }\end{array}$ \\
\cline { 2 - 6 } & $\begin{array}{c}\text { TDS } \\
\text { SENS } \\
\text { OR }\end{array}$ & $\begin{array}{c}\text { TDS } \\
\text { UP } \\
\text { (Water } \\
\text { pump) }\end{array}$ & $\begin{array}{c}\text { TDS } \\
\text { DOWN } \\
\text { (Waterpu } \\
\text { mp) }\end{array}$ & $\begin{array}{c}\text { TDS } \\
\text { (Water } \\
\text { pump) }\end{array}$ & \\
\hline 1 & 1000 & Sedikit & Mati & Sesuai & Sesuai \\
\hline 2 & 1225 & Mati & Mati & Sesuai & Sesuai \\
\hline 3 & 487 & Banyak & Mati & Sesuai & Sesuai \\
\hline 4 & 1808 & Mati & Sedikit & Sesuai & Sesuai \\
\hline 5 & 1400 & Mati & Mati & Sesuai & Sesuai \\
\hline
\end{tabular}

\section{KESIMPULAN DAN SARAN}

\subsection{Kesimpulan}

Setelah dilakukan perangcangan monitoring Tanaman hidroponik dapat ditarik kesimpulan sebagai Berikut:

1. Berdasarkan hasil pengujian fungsional sistem yang telah dilakukan dapat disimpulkan bahwa sistem monitoring Hidroponik dapat bekerja dengan baik.

2. Berdasarkan hasil pengujian Sensor waterlevel, $\mathrm{Ph}$, TDS menunjukan bahwa sensor sudah mendeteksi nilai keluaran yang sudah mendekati dari nilai alat meter untuk mendeteksi kadar setiap sensor.

3. Berdasarkan hasil pengujian Sensor TDS dapat di lihat dari table memiliki rata rata nilai error 2,97\% dan keakuratan data 94\%.

4. Berdasarkan hasil pengujian Sensor Ph dapat di lihat dari table memiliki rata rata nilai error $10 \%$ dan keakuratan data $90 \%$.

5. Berdasarkan pengujian sensor waterlevel yang telah dilakukan dapat disimpulkan bahwa sensor dapat mengirimkan data ketersediaan air ke telegram dengan delay $1-2$ Detik.

6. Berdasarkan hasil pengujian Browser bahwa aplikasi yang dibuat dapat berjalan dengan baik pada web browser Uc Browser, Google Chrome dan Micrisoft Edge semua fungsi pada halaman utama seperti panel data dan panel data grafik berfungsi dengan baik serta semua responsive dari aplikasi dan alat bisa berjalan dengan baik.

7. Berdasarkan hasil pengujian Telegram bawah aplikasi telegram dan Nodemcu sudah bisa melakukan komunikasi dengan baik untuk melakukan pengecekan ketersediaan air pada tendon penyimpanan air jika sudah habis atau pun masoh tersedia dapat di pastikan sensor dan aplikasi bisa berjalan dengan baik

\subsection{Saran}

1. Pengembangan aplikasi monitoring bisa di kembangkan berbasis aplikasi android agar monitoring tanaman hidroponik lebih mudah.

2. Untuk pengembangan lebih lanjut dapat menambahkan sensor sensor yang belum di ngunakan pada penelitian ini seperti sensor cahaya ataupun sensor Suhu.

\section{DAFTAR PUSTAKA}

[1] Adriantri, Emmalia. Irawan, Joseph Dedy. 2018. Implementasi Iot Pada Remote Monitoring Dan Controlling Green House. Jurnal MNEMONIC Informatika Institut Teknologi Nasional Malang, Vol. 1 No. 1, Februari 2018. Malang.

[2] Buanna, Zettry. Candra, Oriza. Elfizon. 2019. Sistem Pemantauan Tanaman Sayar Dengan Media Tanam Hidroponik Menggunakan Arduino. Jurnal Teknik Elektro Universitas Negeri Padang, Vol.V No. 1, Februari 2019. Padang.

[3] "Pengertian Internet of Things (IoT)". SERBA SERBI, TECHNOLOGY. 23 Juni 2016. 10 Maret 2021. https://idcloudhost.com/pengertianinternet-of-things-iot/

[4] Bagas Prartama Putra. 2018. Rancangan Bangun Kandang Ternak Burung Otomatis Berbasis Arduino. Jurnal JATI Informatika Institur Teknologi Nasional Malang, Vol. 2 No. 2, September 2018. Malang.

[5] Rachman, P. N. (2014). SISTEM PENDUKUNG KEPUTUSAN PENJURUSAN DI SMA MENGGUNAKAN FUZZY LOGIC METODE SUGENO BERBASIS WEB. Bandung: Universitas Islam Negeri Sunan Gunung Djati Bandung.

[6] Pranoto, Yosep Agus. Wibowo, Suryo Adi. Dkk . 2018. Implementasi Aplikasi Penghitung Kebutuhan Kalori Penderita Diabetes Melitus Di Lingkungan Klinik. Jurnal MNEMONIC Informatika Intitut Teknologi Nasional Malang, Vol.1, No. 2, September 2018. Malang.

[7] D. Pancawati and A. Yulianto, "Implementasi Fuzzy Logic Controller untuk Mengatur Ph Nutrisi pada Sistem Hidroponik Nutrient Film Technique (NFT)," J. Nas. Tek. Elektro, vol. 5, no. 2, pp. 278-289, 2016.

[8] R. Zamora, Wildian, and Harmadi, "Perancangan Alat Ukur TDS (Total Dissolved Solids) Air dengan Sensor Konduktivitas Secara Real Time," J. Sains dan Teknol., vol. VII, no. 1, pp. 11-15, 2015. 